\title{
The Impact of Relationship Quality on Childbearing in Finland
}

\author{
LASSI LAINIALA, M.Soc.Sc., Researcher \\ The Population Reseach Institute, Väestöliitto, Helsinki Finland
}

\begin{abstract}
Using the data from the 2008 Finnish Well-Being and Social Relationship Survey I examine how relationship quality is associated with childbearing. The respondents are 25-44-year-old married and cohabiting Finns with no or one children in 2008 and who were followed up with register data in 2011. The combined data $(N=1402)$ gives an opportunity to examine the effect of relationship quality to actual births during the period 2008-2011. Different perceptions of current relationship, relationship satisfaction and frequency and reasons of arguing are included to analysis. The independent variables controlling for structural factors include number of children, age and education, both partner's childbearing intention and duration of current relationship. Results indicate that childless men in medium and high quality relationships are most likely to have children. Men (who have a child) in medium quality relationships are most likely to have more children. Relationship quality can shape childless women's childbearing in two ways. Higher relationship quality can strengthen women's intention to have a child and so impact positively on childbearing. Also high relationship quality can result less births among childless women. Women with an earlier child in medium or high quality relationships are most likely to have more children.
\end{abstract}

Keywords: childbearing, relationship quality, quarrelling, domestic conflict, panel data, Finland

\section{Introduction}

It is said that having children will change everything. Having children is one of the most complex decisions people can make in life. This decision includes a decision to take care of a child for a long time. It also makes people to consider their ability to provide the best possible environment for a child to grow up. These important decisions and considerations cannot be made alone. In most cases they have to be negotiated within a couple relationships.

From literature we know that age, parity, partnership and fertility intentions play a determining role in childbearing (see Speder \& Kapitany 2009). Furthermore employment status (Berninger \& al. 2011), income (Andersson 2000), education (Miettinen et al. 2011) and religious affiliation (Frejka \& Westoff 2008; Terämä 2010) all exhibit significant effects. These socio-economic and demographic characters are widely studied in fertility literature. However despite its indisputable importance, the effect of relationship quality 
on fertility decisions has received less scholarly attention yet. It is important to add more empirical evidence to either confirm or to contest the findings of two Dutch Studies (see Rijken \& Liefbroer 2009; Rijken \& Thomson 2010). Most of the remaining studies focus on the effect of union stability on births (Koo \& Janowitz 1983; Myers 1997; Thomson and Heinz 2005).

\section{Theory building and previous findings}

Relationship quality cannot be conceptualized easily because of its multidimensional nature. It includes different aspects like stability, relationship satisfaction and individual-level happiness as well as behavioral dimensions like disagreement and quarrelling (Johnson \& al. 1986; Glenn 1990).

If the relationship quality is so complex concept, how can we measure it reliably? According to Spanier and Lewis (1980) "marital quality is defined as the subjective evaluation of a married couple's relationship on a number of dimensions and evaluations". However, such a loose definition offers too much possible ways to execute measurements. In literature, measurement scales of relationship quality vary from 64-item scales (Hasselbrauck 1997) to just 1-item scales. Schumm (1990) showed that it is possible to find over 50 different measurement scales even under the heading relationship satisfaction. Hassebrauck \& Fehr 2002 performed extensive analysis with different datasets and found that relationship satisfaction was predicted well by the four factors: intimacy, agreement, independence and sexuality.

There are some interesting approaches considering relationship quality's impact on fertility. A theory of the value of children/uncertainty reduction theory of parenthood (Friedman \& al. 1994) suggested among many other hypotheses that couples who lack marital solidarity and are unhappy with their marriages might use childbearing as a strategy to increase solidarity and, in turn reduce marital uncertainty. This may be true in some cases but many studies (Myers 1997; Hobcraft \& Kiernan 1995; Lillard \& Waite 1993) have shown that a solid partnership encourages parenthood and higher-order childbearing.

Empirical analysis performed by Rijken \& Liefbroer (2009) and Rijken \& Thomson (2010) can be placed somewhere in the middle of these two opposing views. Results of the former Dutch study about couple interaction indicate that "highest rates of childbearing seemed to occur among couples with relationships that were basically sound but not of the highest quality" and the latter that "only women's perceptions of relationship quality influence a first birth, whereas women's and men's perceptions affect second births[...] women reporting medium levels of relationship quality are most likely to have a(nother) child whereas men with medium and high quality relationships are most likely to have a second child". 
There is no easy interpretation for these competing views. Could it be that high couple interaction or relationship satisfaction produce side effects like fears of losing a great relationship if children came into picture. So people in medium quality relationships would be more immune to different inputs and having a child would not be a danger which will ruin their relationship. On the other hand, individuals with lower or medium levels of satisfaction in their relationship may plan having children in order to provide alternative sources or objects of love or try to increase the quality of the relationship itself (Bulatao 1981; Seccombe 1991), in a way corresponding to the reduction of uncertainty hypothesis discussed earlier.

In addition, some studies have found that individuals express concerns about childbearing's negative effects on their relationships (Carmichael \& Whittaker 2007). That is a rational concern because we know from empirical research that relationship quality suffers from post birth deterioration (Doss \& al. 2009).

Individuals who already have a child should have learn something about that, how a child, an additional element of a couple relationship may effect to couple relationship. Then one can assume that having a better relationship quality increases odds for having an additional child.

Why people then risk their relationship and have children? One reason might be that they do not know what kind of consequences childbearing might have. Another reason might be that people know there can be negative consequences but they think it will not happen to them or maybe they think that their relationship is strong enough and a child adds just an additional element to it. The decision to have a child must also include many irrational or biological elements like lust and baby fever so childbearing cannot be completely based on rationality or explained by socio-demographic and relationship quality-related factors.

In most of the measurement attempts of relationship quality, some compromises have to be made. For example Rijken \& Thomson (2010) built a 13-item factor to measure relationship quality. Their factor covered almost every aspect of relationship quality. However, it did not cover really important components of relationship quality like intimacy or sexuality.

Relationship quality should be measured more extensively. Building just one factor cannot be considered as a poor choice. More important thing is that this factor is valid and predicts well things like relationship stability, relationship satisfaction and frequency of arguing. Poor relationship satisfaction, unstable union and frequent arguing can be expected to diminish relationship quality. Building a bulletproof factor may yet be impossible, because people deal with different inputs in different ways: One can end a relationship if for example housework is not shared equally but another one can argue about it in order to increase his/her relationship quality. 
However, I assume that childbearing in Finland generally follows rational paths. One can criticize me that people can't make rational decisions considering childbearing because it is so emotionally loaded decision and a vast body of social research reveals that people often act impulsively and emotionally. Yes, that is true. Most individuals make some irrational choices all the time. At the same time, an overall outcome can yet be very rational.

Based on the previous findings and theoretical ideas I form hypotheses about relationship quality's impact on childbearing in Finland.

I interpreted based on earlier research that individuals (0-parity) in high quality relationships can be more vulnerable for fears about losing their great relationship. I also assumed that (1-parity) parents have experienced how having a child affect their relationships, so they should be more able to calculate the consequences of another child. That would mean that childless couples in medium quality relationships would have increased odds for childbirth and parents in high quality relationships would have increased odds for childbirth. However, because couples are normally expected to have children and stay together for a long time I assume that high relationship quality would provide the best environment to have children. Parents should have a same kind of thinking patterns. So my main hypothesis will be:

H1. Childless individuals in high quality relationships are most likely to have children

H2. Parents in high quality relationships are most likely to have children

I also test the "child will ruin the great relationship"-hypothesis

H3. Childless individuals in medium quality relationships are most likely to have children because they have fears of a child's negative impact on their relationship quality.

This article examines how relationship quality, as reported in a survey predict actual childbearing in the 3 subsequent years. I study what kind of couple relationship increases childbearing among those 25-44-year-old male and female Finns with no or one children. Different perceptions of current relationship and frequency and reasons of arguing are included to analysis. Both married and cohabiting are examined. Attention to childbearing also within non-marital unions is important because the rising number of children is born within such unions in Finland and also throughout Western world. 


\section{Method}

\section{Data}

The Finnish Well-being and Social Relationships Survey was carried out by Väestöliitto, the Family Federation of Finland in 2008 among 7000 25-44-year-old men and women who had no children or only one child. It received a $44 \%$ response rate (Miettinen \& Rotkirch 2008). The study focused on low parity adults and so parents with two or more children were excluded. The questionnaire asked about various aspects of personal and marital well-being, attitudes and expectations towards work, relationship quality, family and social relationships as well as childbearing ideals and intentions. In 2011 this survey data was combined with a panel data of Population Register Centre of Finland among those individuals who had given a permission to do so. The combined data gives an opportunity to examine the effect of relationship quality to actual births during the period 2008-2011. The number of respondents in the combined data is 1981 . The sample size I use in this paper is 1402 due to including only married or cohabiting individuals and due to some missing information in this sample.

Because of a limited time period, only relationship quality's effect on prompt childbearing can be examined here. Also changes in relationship quality during 2008-2010 cannot be examined with this data. People who died (2) or moved abroad during the examination period (11) were excluded from the analysis.

\section{Variables}

\section{Childbirth}

The dependent variable in this study is that individual had a child or not $(0=$ no, $1=$ yes $)$ during 2008-2011.

Relationship satisfaction and quarrelling. Questions about current relationship satisfaction are seen in this paper as a one component of relationship quality. Responses to following statements (11) were measured with five-item scale ('strongly disagree' to 'strongly agree'): "I am satisfied how household chores and obligations are shared between me and my partner", "I am satisfied how we express feelings and thoughts to each other", "I feel that my partner does not understand me", "I am satisfied with quantity of intimacy in my relationship", "I feel that my partner does not appreciate me", "I feel that we do not love each other", "I am satisfied with the way we deal with conflicts in our relationship", "My partner fully supports me in my life", "I am satisfied with sex in current relationship", "I am satisfied how we spend time together" , "I am satisfied with the way we make decisions about money and household finances", "My partner does not understand me (reversed)", "My partner does not appreciate me (reversed)" and "We are together just because of the children (reversed)". 
A factor analysis with Maximum likelihood method was executed for these statements. Due to low number of missing data (from $0,6 \%$ to $1,5 \%$ ) in these questions missing values were replaced by an average value of each statements in order to include all respondents to analysis.

The analysis returned very complicated results. If whole dataset is analyzed (a question about children excluded), factor analysis show that one-factor solution is highly preferable over multi-factor solutions. However, splitting the data into groups of 0 and 1-parities and men and women will return different output including multiple factor solutions. This kind of result simply shows that overall relationship satisfaction builds differently among different groups. It does not mean we cannot measure relationship quality with just one factor. That is why these variables were analyzed with variables expressing arguing within relationship the following way.

The data of Finnish Well-Being and Social Relationships Survey includes also 11 questions about reasons and frequency of different kind of arguments. Responses were obtained by asking with five-item scale (categories from 'never' to 'very often') how often a respondent has arguments with a partner about different topics. Topics for quarrelling were:"sharing housework","financial matters","use of free time","sex","friendship relations","relations to own parents and relatives","relations to spouses parents and relatives","alcohol and intoxicating substances","own employment or studies","spouses employment or studies", "'Infidelity or jealousy" and "raising the children". All these variables were reversed before analysis. Also these variables were low on missing data so similar value imputation made above was conducted.

Series of new factor analyses with Maximum likelihood method for (22) variables were executed. There would have been several different possibilities to continue the analysis. However producing different factors for different groups would have produced results which are highly difficult to interpret. Finally just two factors were built (Cronbach's alpha 0.91/0.90). One factor was for 0-parity and another for 1-parity (including questions about children. These factors correlate extremely highly $(0.98 * * *)$ with each other, so they can be trustworthy considered to measure the same dimension. Factors are normally distributed.

To validate the measurement scale it's correlations was tested with questions about different forms of satisfaction which were included to the dataset I'm using (table 1.) Regarding childless individuals, the factor correlated well with a variable which measures relationship stability (thoughts of divorce) and satisfaction to current couple relationship. Regarding parents the result is similar. However, relationship quality-factor does not correlate well enough with satisfaction-variable about parenthood. That indicates that relationship quality-factor misses some elements about experiences of parenthood. So the parenthood variable is included to analysis later on as a separate variable. 
Table 1. Correlations between relationship quality-factor and satisfaction variables.

\begin{tabular}{lcc}
\hline & $\begin{array}{c}0-\text { parity } \\
\text { (N=492) }\end{array}$ & $\begin{array}{c}1-\text { parity } \\
\text { (N=910) }\end{array}$ \\
\hline Thought of divorce (not at all->very often) & $\begin{array}{c}-0.592^{* * * *} \\
-0.619 * * *\end{array}$ \\
Satisfied with couple relationship (very dissatisfied->very satisfied) & $\begin{array}{c}-0.739 * * * \\
\text { Satisfied with family life (very dissatisfied->very satisfied) }\end{array}$ & $0.755^{* * *}$ \\
Satisfied with parenthood (very dissatisfied->very satisfied) & $0.628 * * *$ \\
\hline
\end{tabular}

\section{Control variables and re-coding}

Literature on fertility shows that sex, age, parity, education and union status (Miettinen \& Rotkirch 2011; Speder \& Kapitany 2009), childbearing intentions and the partner's childbearing intentions (Thomson \& Hoem 1998), duration of current relationship (Rijken \& Thomson 2010) and income/partner's income (Berninger \& al. 2011) all have an effect on childbearing. Including these commonly used control variables regarding childbearing into analysis lowers the risk to produce a false association between relationship quality and childbearing. It must also be taken in account that socio-demographic factors can be associated through complex social processes with all childbearing, childbearing intentions and relationship quality. In addition, a control variable about age of a youngest child (recoded 0-2/3-6/7-17) and two variables to test "childbearing will ruin the relationship quality" and "uncertainty reduction"-hypotheses discussed earlier in this paper was included. Scale variable about age of the youngest child was corrupted so the recoded variable had to be used.

Both women's and men's age and age squared are included. Educational status was re-coded into three categories (lower vocational or less-middle level vocationaluniversity level education) and union status into two categories (cohabiting-married). Due to high number of missing data in variables about childbearing intentions a new variable that gives a very rough picture about respondent's and his/her partner's childbearing intentions (intention to have a child-doesn't intend/doesn't now) had to be built. Using more accurate variables would have led to too small sample size. Partner's childbearing intention is reported by the respondent so it's reliability is a bit questionable. A complete list about the variables which are used in analysis can be found from the table 2 . 


\section{Statistical analyses}

Analysis is made separately for men and women and for 0- and 1-parities because reproductive behavior is known to be different in these groups.

First, logistic regression analysis is used to examine the impact of relationship quality on births. The analysis will result three different models. In first model sociodemographic variables are controlled. In second model socio-demographic and couple relationship-related variables are controlled. In third model all control variables are put into same model.

Second, possible curvilinear associations between relationship quality and births are tested by adding a quadratic term into analysis. Interactions between relationship quality and childbearing intentions are also tested.

Finally, possible curvilinear effects for all groups (0/1-parity, men/women) are calculated. Results can be found from figure 1 (control variables are from the regression model II).

Using Cox regression or other proportional hazard models was not necessary due to limited time period ( 3 years) and due to eliminating risk factors like deaths and migrations.

\section{Results}

\section{Descriptive statistics}

Descriptive characteristics for 0- and 1-parity men and women are presented in a table 2. About $35 \%$ of childless men and women had a child during the examination period. Higher number of parents had an additional child. About $46 \%$ of men and $51 \%$ of women who already have a child had a child during the examination period. Relationship quality in both 0- and 1-parities is higher among men. However a standard deviation among women is higher. Distributions of other variables can be read from the table.

Table 2. Descriptive characteristics of the sample.

\begin{tabular}{lcccc}
\hline \multicolumn{1}{c}{ Variable } & $\begin{array}{c}\text { Men. no } \\
\text { children } \\
(\mathrm{N}=189)\end{array}$ & $\begin{array}{c}\text { Women. } \\
\text { no children } \\
(\mathrm{N}=303)\end{array}$ & $\begin{array}{c}\text { Men. } \\
1 \text { child } \\
(\mathrm{N}=448)\end{array}$ & $\begin{array}{c}\text { Women. } \\
1 \text { child } \\
(\mathrm{N}=462)\end{array}$ \\
\hline $\begin{array}{l}\text { Had a child during 2008-2010 (\%) } \\
\text { Relationship quality }\end{array}$ & 35.4 & 35.6 & 46.3 & 51.1 \\
$\begin{array}{l}\text { Mean } \\
\text { Standard deviation }\end{array}$ & 0.29 & 0.09 & 0.04 & -0.04 \\
Union status (\%) & 0.86 & 0.92 & 0.88 & 1.04 \\
$\begin{array}{l}\text { Cohabiting } \\
\text { Married }\end{array}$ & 38.1 & 36 & 68.5 & 65.8 \\
Intention to have a child (\%) & 61.9 & 64 & 31.5 & 34.2 \\
Yes & & & & \\
Do not know/Does not want & 58.7 & 59.1 & 58.3 & 58.3 \\
\hline
\end{tabular}




\begin{tabular}{|c|c|c|c|c|}
\hline Variable & $\begin{array}{l}\text { Men. no } \\
\text { children } \\
(\mathrm{N}=189)\end{array}$ & $\begin{array}{c}\text { Women. } \\
\text { no children } \\
(\mathrm{N}=303)\end{array}$ & $\begin{array}{l}\text { Men. 1 child } \\
(\mathrm{N}=448)\end{array}$ & $\begin{array}{c}\text { Women. } \\
1 \text { child } \\
(\mathrm{N}=462)\end{array}$ \\
\hline \multicolumn{5}{|c|}{ Spouse's intention to have a child (\%) } \\
\hline Yes & 78.3 & 75.2 & 74.8 & 73.8 \\
\hline Don't know/Does not want & 21.7 & 24.8 & 25.2 & 26.2 \\
\hline \multicolumn{5}{|l|}{ Age (grouped) (\%) } \\
\hline $25-29$ & 36.5 & 46 & 25.7 & 33.2 \\
\hline $30-34$ & 29.1 & 20.5 & 33 & 33 \\
\hline $35-39$ & 19.6 & 18.2 & 22.5 & 18.2 \\
\hline $40-44$ & 14.8 & 15.2 & 18.8 & 15.6 \\
\hline \multicolumn{5}{|l|}{ Education (\%) } \\
\hline High & 24.6 & 35 & 29.1 & 30.7 \\
\hline Middle & 40.1 & 25.7 & 41.9 & 28.4 \\
\hline Low & 35.3 & 39.3 & 28.9 & 40.9 \\
\hline \multicolumn{5}{|l|}{$\begin{array}{l}\text { Monthly income after taxes }(€) \\
\text { Own income }\end{array}$} \\
\hline Mean & 1864 & 1576 & 2081 & 1409 \\
\hline Median & 1800 & 1530 & 2000 & 1400 \\
\hline Standard deviation & 726 & 553 & 815 & 672 \\
\hline \multicolumn{5}{|l|}{ Spouse's income } \\
\hline Mean & 1532 & 1929 & 1354 & 2005 \\
\hline Median & 1500 & 1900 & 1400 & 1900 \\
\hline Standard deviation & 991 & 827 & 715 & 894 \\
\hline \multicolumn{5}{|l|}{ Age first child (years) } \\
\hline $0-2$ & & & 63.4 & 63.6 \\
\hline $3-6$ & & & 16.8 & 17.4 \\
\hline $7-17$ & & & 19.9 & 19 \\
\hline \multicolumn{5}{|l|}{ Relationship duration (years) } \\
\hline Mean & 5.1 & 5.9 & 6.8 & 6.5 \\
\hline Standard deviation & 4.1 & 4.6 & 4.6 & 4.6 \\
\hline \multicolumn{5}{|c|}{ Having children will lead to better relationship quality } \\
\hline Strongly disagree & 7.4 & 8.9 & 8.9 & 8.4 \\
\hline Disagree & 12.7 & 16.9 & 16.9 & 21.1 \\
\hline Neither agree nor disagree & 44.4 & 43.4 & 43.4 & 37.8 \\
\hline Agree & 29.1 & 26.8 & 26.8 & 27.8 \\
\hline Strongly Agree & 6.3 & 4 & 4 & 4 \\
\hline \multicolumn{5}{|c|}{ Having children will reduce uncertainty in life } \\
\hline Strongly disagree & 26.5 & 24 & 16.8 & 25 \\
\hline Disagree & 23.8 & 35.3 & 30.3 & 29.2 \\
\hline Neither agree nor disagree & 37 & 27.3 & 39.9 & 35.9 \\
\hline Agree & 11.6 & 10.7 & 11.7 & 8.5 \\
\hline Strongly Agree & 1.1 & 2.7 & 1.4 & 1.3 \\
\hline \multicolumn{5}{|l|}{ Satisfied with parenthood } \\
\hline Very dissatisfied & & & 0.7 & 0 \\
\hline Dissatisfied & & & 2.3 & 0.7 \\
\hline Neither dissatisfied nor satisfied & & & 8.6 & 6.5 \\
\hline Satisfied & & & 48.4 & 53 \\
\hline Very satisfied & & & 40.1 & 39.8 \\
\hline
\end{tabular}




\section{The Firstborn}

Table 3 shows odds ratios of having a first child for childless men and women.

\section{Men}

Men's relationship quality's association with having a first child is statistically significant in all three models.

Men's childbearing intention regarding the first child is not statistically significant. Spouse's childbearing intention is statistically significant in second model but when future views about the meaning of a child are controlled, it is not. The quadratic term of relationship quality is not statistically significant. However it indicates some curvilinear association (univariate analysis not shown, available on request) but curve turns slightly after average value. It indicates that childless men in medium and high quality relationships have increased odds for having a child. Results also indicate that spouse's monthly income after taxes have an positive association with childbearing. It could indicate that men appreciate financially independent women when planning a first child. Interaction term (intention to have a child * relationship quality) is not statistically significant regarding men.

\section{Women}

Women's relationship quality's association with having a first child is not statistically significant in any models. Intention to have a child seems to play a very important role regarding firstborns. Preliminary analysis indicates no curvilinear association between women's relationship quality and births. However, adding an interaction term (intention to have a child * relationship quality) into model results changes in estimates. Interaction is statistically significant and it indicates that better relationship quality works through childbearing intention. However at the same time adding an interaction term turns relationship quality-variable to be significant. It could indicate that for some women higher relationship quality leads to intention to have a child/ more solid intention to have a child and for some women high relationship quality decreases odds of having children.

\section{Hypothesis III}

Results concerning "childbearing will ruin the relationship quality" and "uncertainty reduction hypothesis" are the following. There are some indications that if the respondent thinks that childbearing will not ruin the relationship he/she will have increased odds for births. However men's figures indicate curvilinear relationship. If respondent thinks that having children will reduce uncertainty in life he/she will have increased odds for births. However, these results are not statistically significant and do not increase the explanation power of the model. 
Table 3. Logistic regression. Odds ratio estimates of having the firstborn.

\begin{tabular}{|c|c|c|c|c|c|c|c|}
\hline & & \multicolumn{2}{|c|}{ Model I } & \multicolumn{2}{|c|}{ Model II } & \multicolumn{2}{|c|}{ Model III } \\
\hline & & Men & Women & Men & Women & Men & Women \\
\hline Relationship Quality & & $2.882^{*}$ & 1.390 & $2.345^{*}$ & 1.120 & $3.085^{*}$ & 1.248 \\
\hline $\begin{array}{l}\text { Relationship Quality **2 } \\
\text { (quadratic term) }\end{array}$ & & 0.601 & 1.120 & 0.704 & 1.010 & 0.681 & 1.093 \\
\hline Age & & 2.199 & $3.575^{\star}$ & 1.780 & 2.151 & 1.422 & 2.294 \\
\hline Age Squared & & 0.986 & $0.978^{*}$ & 0.990 & 0.986 & 0.993 & 0.985 \\
\hline \multirow[t]{3}{*}{ Education } & High & 1.000 & 1.000 & 1.000 & 1.000 & 1.000 & 1.000 \\
\hline & Medium & 0.550 & 1.544 & 0.892 & 1.240 & 0.823 & 1.150 \\
\hline & Low & 1.148 & 1.413 & 1.840 & 1.077 & 1.995 & 1.081 \\
\hline \multirow[t]{2}{*}{ Monthly Income } & $\begin{array}{l}\text { Monthly income } \\
\text { after taxes }\end{array}$ & 1.094 & 1.119 & 1.146 & 1.076 & 1.166 & 1.067 \\
\hline & $\begin{array}{l}\text { Spouse's } \\
\text { monthly income } \\
\text { after taxes }\end{array}$ & 1.166 & $1.413^{*}$ & $1.508+$ & 1.285 & $1.663+$ & 1.308 \\
\hline \multirow[t]{2}{*}{ Union status } & Cohabiting & & & 1.000 & 1.000 & 1.000 & 1.000 \\
\hline & Married & & & 0.512 & 1.547 & 0.488 & 1.590 \\
\hline \multirow[t]{2}{*}{ Intention to have a child (\%) } & $\begin{array}{l}\text { Do not know/ } \\
\text { Does not want }\end{array}$ & & & 1.000 & 1.000 & 1.000 & 1.000 \\
\hline & Yes & & & 3.567 & $7.366^{* *}$ & 4.442 & $6.764^{* \star}$ \\
\hline \multirow[t]{2}{*}{$\begin{array}{l}\text { Spouse's intention to have } \\
\text { a child }(\%)\end{array}$} & $\begin{array}{l}\text { Don't know/Does } \\
\text { not want }\end{array}$ & & & 1.000 & 1.000 & 1.000 & 1.000 \\
\hline & Yes & & & $5.982^{*}$ & 1.457 & 5.672 & 1.338 \\
\hline Relationship duration & & & & 0.930 & 0.994 & 0.928 & 0.993 \\
\hline \multicolumn{8}{|l|}{$\begin{array}{l}\text { Future prospects (strongly } \\
\text { disagree -> strongly agree) }\end{array}$} \\
\hline $\begin{array}{l}\text { Having children will lead to } \\
\text { better relationship quality }\end{array}$ & & & & & & 6.131 & 1.260 \\
\hline $\begin{array}{l}\text { Having children will lead to } \\
\text { better relationship quality**2 }\end{array}$ & & & & & & 0.682 & 0.990 \\
\hline $\begin{array}{l}\text { Having children will reduce } \\
\text { uncertainty in life }\end{array}$ & & & & & & 1.496 & 1.360 \\
\hline Nagelkerke R Square & & 0.27 & 0.28 & 0.45 & 0.36 & 0.51 & 0.38 \\
\hline
\end{tabular}




\section{The Second Born}

Table 4 shows odds ratios of having a second child for parents.

\section{Men}

Men's relationship quality's association with having a second child is not statistically significant in any model. Men's intention to have a second child is statistically significant in all models whereas his spouse's intention is not. Higher monthly income indicates higher odds for a child. Also a young first child increases odds for a second one. Quadratic term of relationship quality is significant, so it indicates that 1-parity men in medium quality relationships have increased odds for having another child. Interaction term (intention to have a child * relationship quality) is not statistically significant for 1-parity men.

\section{Women}

Women's relationship quality's association with having a second child is statistically significant in all models. It indicates there is almost a linear association with births. However noticing the quadratic term it also means that women in medium and high quality relationships are most likely to have additional children. Women's intention to have a child is also significant in all models. Longer relationship duration but at the same time young first child indicates higher odds for a birth. Higher monthly income decreases the odds for having a second child. It could mean that career oriented women postpone having a second child and maybe have it later. Interaction term (intention to have a child * relationship quality) is not statistically significant for 1-parity men.

\section{Hypothesis III}

Satisfaction with parenthood (although not significant) seems to have different effects for men and women. Positive experiences about parenthood seem to increase men's willingness and decrease women's willingness for another child. Future views about another child's meaning to the relationship seem to have no effect. 
Table 4. Logistic regression. Odds ratio estimates of having the second born.

\begin{tabular}{|c|c|c|c|c|c|c|c|}
\hline & & \multicolumn{2}{|c|}{ Model I } & \multicolumn{2}{|c|}{ Model II } & \multicolumn{2}{|c|}{ Model III } \\
\hline & & Men & Women & Men & Women & Men & Women \\
\hline Relationship Quality & & 1.209 & $1.463^{*}$ & 0.864 & $1.863^{* *}$ & 0.780 & $1.964^{* *}$ \\
\hline $\begin{array}{l}\text { Relationship Quality **2 } \\
\text { (quadratic term) }\end{array}$ & & $0.755+$ & 0.849 & 0.707 & 1.007 & $0.673+$ & 1.044 \\
\hline Age & & $2.786^{*}$ & 2.077 & 1.589 & 0.807 & 1.491 & 0.781 \\
\hline Age Squared & & $0.983^{* *}$ & $0.986+$ & 0.992 & 1.000 & 0.993 & 1.001 \\
\hline \multirow[t]{3}{*}{ Education } & High & 1.000 & 1.000 & 1.000 & 1.000 & 1.000 & 1.000 \\
\hline & Medium & 0.720 & 0.597 & 0.626 & $0.729^{*}$ & 0.570 & 0.784 \\
\hline & Low & $0.496+$ & $0.390+$ & 0.489 & 1.025 & 0.461 & 1.081 \\
\hline \multirow[t]{2}{*}{ Monthly income } & $\begin{array}{l}\text { Monthly income } \\
\text { after taxes }\end{array}$ & $1.279^{*}$ & $0.700^{* *}$ & $1.336+$ & $0.729^{*}$ & $1.329+$ & $0.729^{*}$ \\
\hline & $\begin{array}{l}\text { Spouse's monthly } \\
\text { income after taxes }\end{array}$ & 1.075 & 1.1117 & 1.054 & 1.128 & 1.073 & 1.149 \\
\hline \multirow[t]{2}{*}{ Union status } & Cohabiting & & & 1.000 & 1.000 & 1.000 & 1.000 \\
\hline & Married & & & $2.039+$ & 0.977 & $2.165+$ & 0.899 \\
\hline \multirow[t]{2}{*}{ Intention to have a child \%) } & $\begin{array}{l}\text { Do not know/ } \\
\text { Does not want }\end{array}$ & & & 1.000 & 1.000 & 1.000 & 1.000 \\
\hline & Yes & & & $7.301^{* * *}$ & $7.359^{* * *}$ & ${ }^{*} 6.833^{* *}$ & $7.164^{* * *}$ \\
\hline \multirow[t]{2}{*}{$\begin{array}{l}\text { Spouse's intention to have } \\
\text { a child (\%) }\end{array}$} & $\begin{array}{l}\text { Don't know/Does } \\
\text { not want }\end{array}$ & & & 1.000 & 1.000 & 1.000 & 1.000 \\
\hline & Yes & & & 1.207 & 2.567 & 0.930 & 2.793 \\
\hline Relationship duration & & & & 1.092 & $1.147^{*}$ & 1.102 & $1.148^{*}$ \\
\hline \multirow[t]{3}{*}{ Age first child } & $0-2$ years & & & 1.000 & 1.000 & 1.000 & 1.000 \\
\hline & & & & $0.014^{* * *}$ & $0.077^{\star *}$ & $0.013^{* * *}$ & $0.071^{* *}$ \\
\hline & $7-17$ years & & & $0.328^{*}$ & 0.576 & $0.300^{*}$ & 0.532 \\
\hline $\begin{array}{l}\text { Satisfied with parenthood (very } \\
\text { dissatisfied->very satisfied) }\end{array}$ & & & & & & 1.401 & 0.729 \\
\hline \multicolumn{8}{|l|}{$\begin{array}{l}\text { Future prospects (strongly } \\
\text { disagree -> strongly agree) }\end{array}$} \\
\hline $\begin{array}{l}\text { Having children will lead to } \\
\text { better relationship quality }\end{array}$ & & & & & & 0.954 & 1.157 \\
\hline $\begin{array}{l}\text { Having children will reduce } \\
\text { uncertainty in life }\end{array}$ & & & & & & 0.928 & 0.994 \\
\hline Nagelkerke R Square & & 0.33 & 0.46 & 0.55 & 0.59 & 0.54 & 0.58 \\
\hline
\end{tabular}




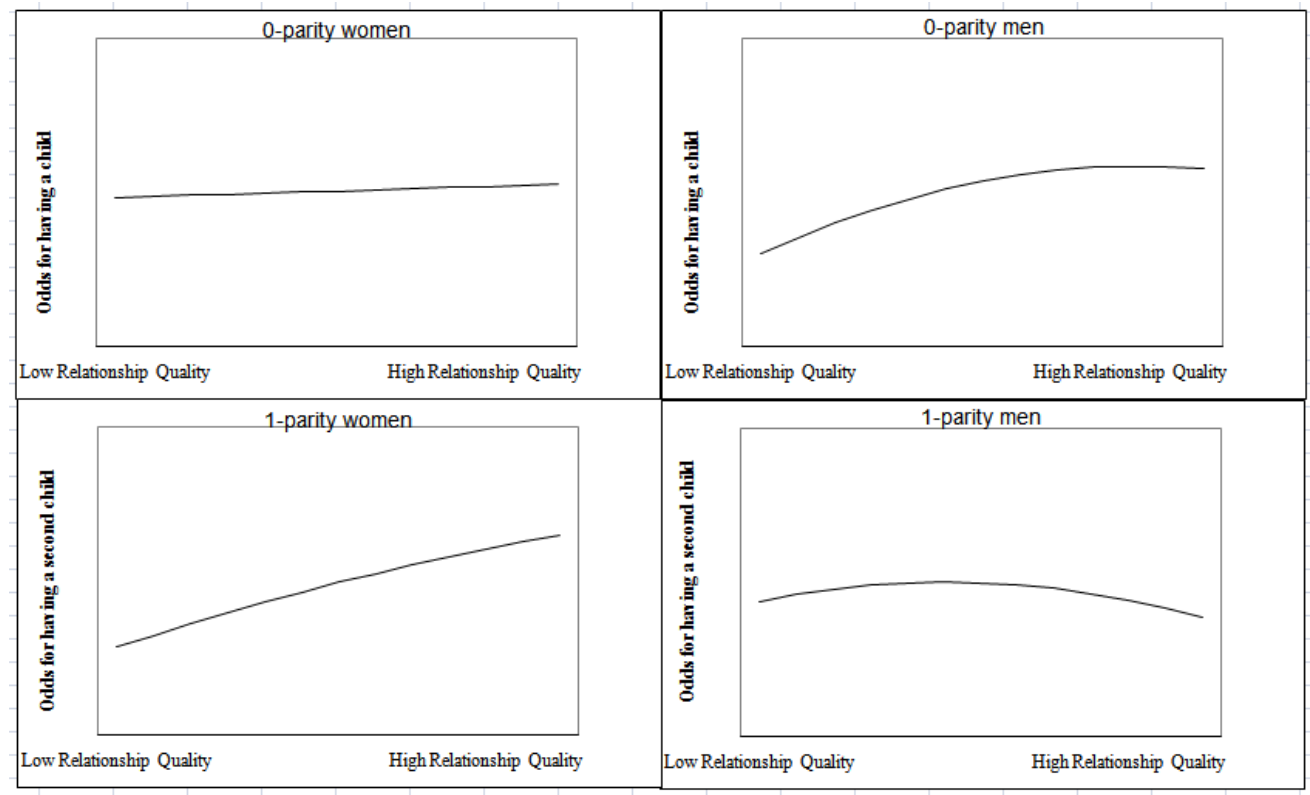

Figure 1. Curvilinear effects of relationship quality's impact on births.

\section{Discussion}

The objective of this study was to examine if the couple relationship quality have an impact on probability of births in Finland. On the focus of this study was 0 - and 1-parity 25-44-year-old married and cohabiting Finns who answered the questionnaire in 2008 and their fertility was followed up by panel data in 2011.

The existing literature on this topic presents quite a mixed picture about relationship satisfaction's impact on childbearing. However the data and questions designed to measure relationship satisfaction and/or quality differs from one study to another and all important factors regarding relationship quality are not available in most datasets. In this study some important elements like sexuality/intimacy which is missing from many other datasets are included to analysis.

Three hypotheses were formed: (H1) Childless individuals in high quality relationships are most likely to have children, (H2) Parents in high quality relationships are most likely to have children and (H3) Childless individuals in medium quality relationships are most likely to have children because they have fears of a child's negative impact on their relationship quality.

Results were the following. Childless men in medium and high quality relationships are most likely to have children. Men (who have a child) in medium quality relationships are most likely to have children. Regarding childless women the picture is more complicated. Only childbearing intention seemed to play a determining role. How after 
exploring interactions analysis resulted that higher relationship quality strengthens the impact of intention to have a child. At the same time analysis indicated that higher relationship quality had a negative effect on births. This kind of result does not necessarily mean that there is a curvilinear or non-linear association. It can also mean that there are different kinds of childless women. For some high relationship quality increases and for some it decreases odds for birth. Women (who have a child) in medium and high quality relationships are most likely to have children.

The first hypothesis was almost correct regarding men but analysis regarding women showed that relationship quality's effect is not so straightforward. Relationship quality can simply shape childbearing in different ways. Second hypothesis were correct regarding women but not for the men. Third hypothesis cannot be confirmed as a true one. As we could see in descriptive statistics almost same amount of individuals thought that having a child will improve the relationship quality and that having a child will reduce it. Again, there are many different thinking patterns that can result a same outcome: Having a child. It was also assumed that people will act rationally. Because there was no indication that people will had more children in low quality relationships it should be confirmed. Ideal socio-demographic status plus medium or high relationship quality will result higher odds to have children. That is rational behavior.

Although these results differ slightly from Rijken's and Thomson's (2010), it is confirmed that low relationship quality does not increase odds for having a child. They didn't have possibility to control childbearing intentions which could have resulted a different output.

However, the sample size which was used in this study can be considered as small one. Sample might be also a bit biased because it misses people who have had two children before they were 25 years old. So the results should be interpreted with a certain caution.

To conclude, I suggest that measurements of relationship quality should be integrated to future research to achieve a deeper understanding about meaning of intentions and interactions between these factors. In addition, future research could solve what are the most important elements of relationship quality for different groups which have an impact on childbearing.

\section{References}

Andersson, G. 2000. The impact of labour-force participation on childbearing behavior: Pro-cyclical fertility in Sweden during the 1980s and the 1990s. European journal of population, 16(4):293-333.

Berninger I., B. Weiss, and M. Wagner. 2010. On the links between employment, partnership quality, and the intention to have a first child: The case of West Germany. Demographic Research, 24, 579-610. Available from: http://www.demographicresearch.org/volumes/vol24/24/24-24.pdf 
Bulatao, R. A. 1981. Values and disvalues of children in successive childbearing decisions. Demography, 18(1):1-25.

Carmichael, G. A. and A. Whittaker. 2007. Choice and circumstance: Qualitative insights into contemporary childlessness in Australia. European Journal of Population, 23(2):111-143.

Doss, B., G. Rhoades, S. Stanley and J. Markman. 2009. The Effect of the Transition to Parenthood on Relationship Quality: An Eight-Year Prospective Study. Journal of Personality \& Social Psychology, 96(3):601-619.

Glenn, N. D. 1990. Quantitative research on marital quality in the 1980s: A critical review. Journal of Marriage and the Family, 52(4): 818-831.

Frejka, T. and W. Westoff. 2008. Religion, Religiousness and Fertility in the US and in Europe. European Journal of Population, 24(1): 5-31.

Friedman, D and M. Hechter. 1994. A theory of the value of children. Demography, 31(3):375-401.

Hassebrauck, M. 1997. Cognitions of relationship quality: A prototype analysis of their structure and consequences. Personal Relationships, 4(2):163-185.

Hassebrauck, M. and B. Fehr. 2002. Dimensions of Relationship Quality. Personal Relationships, 9(3):253-270.

Hobcraft, J. and K. Kiernan. 1995. "Becoming a parent in Europe", Discussion Paper WSP/116, Welfare State Programme. London: The Toyota Centre, London School of Economics.

Johnson, D. R., L.K. White, J.N. Edwards, and A. Booth. 1986. Dimensions of marital quality: Towards methodological and conceptual refinement. Journal of Family Issues, 7(1):31-49.

Koo, H. P., and B.K. Janowitz. 1983. Interrelationships between fertility and marital dissolution: Results of a simultaneous logit model. Demography, 20(2):129-145.

Lillard, L. A. and J.L. Waite. 1993. A joint model of marital childbearing and marital disruption. Demography, 30(4):653-681.

Miettinen, A., S. Basten and A. Rotkirch. 2011. Gender equality and fertility intentions revisited. Evidence from Finland. Demographic Research, 24, 469-496. Available from:http:/www.demographic-research.org/Volumes/Vol24/20/24-20.pdf

Miettinen, A. and A. Rotkirch. 2008. Milloin on lapsen aika? Lastenhankinnan toiveet ja esteet. [When is the right time for children? Fertility intentions and barriers]. E/34. Helsinki: Family Federation of Finland, Population Research Institute.

Myers, S. M. 1997. Marital uncertainty and childbearing. Social Forces, 75(4): 1271-1289.

Rijken, A. J. and A.C. Liefbroer. 2009. Influences of the family of origin on the timing and quantum of fertility in the Netherlands. Population Studies, 63(1):71-85.

Rijken, A.J. and E. Thomson. 2010. Partners' Relationship Quality and Childbearing. Research Reports in Demography 4. Stockholm: Stockholm University.

Seccombe, K. 1991. Assessing the costs and benefits of children: Gender comparisons among childfree husbands and wives. Journal of Marriage and the Family, 53(1):191-202. 
Schumm, W. R. 1990. Intimacy and family values. In Handbook of family measurement techniques, edited by J. Touliatos, B. F. Perlmutter and M. A. Straus, pp. 164-284. London: Sage.

Spanier, G. B. and R.A. Lewis. 1980. Marital quality: A review of the seventies. Journal of Marriage and the Family, 42(4):825-839.

Speder, Z. and B. Kapitany. 2009. How are Time-Dependent Childbearing Intentions Realized? Postponement, Abandonment, Bringing Forward. European Journal of Population, 25(4):503-523.

Thomson, E., \& Heinz, U. 2005. Union stability and stepfamily fertility in Austria, Finland, France \& West Germany. European Journal of Population, 21(1):3-29.

Terämä, E. 2010. Regional demographic differences: The Effect of Laestadians. Finnish Yearbook of Population Research 2010, pp. 123-140. 